
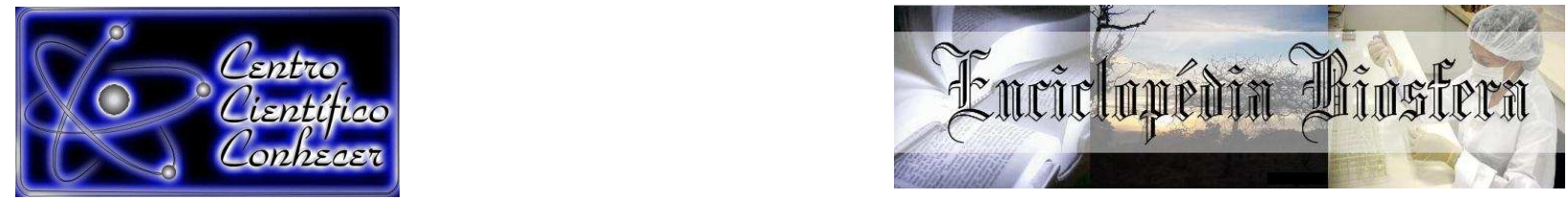

\title{
ISOLAMENTO, IDENTIFICAÇÃO E AVALIAÇÃO DAS ATIVIDADES ENZIMÁTICA E ANTIBACTERIANA DE MICRO-ORGANISMOS ENDOFÍTICOS DE Hyptis suaveolens (L.) Poit.
}

Edweis Cândida Barbosa1, Aysha Jussara Ivonilde Carrim², Bruno Francesco Rodrigues de Oliveira ${ }^{3}$, Igor Daniel Alves Ribeiro ${ }^{4}$, José Daniel Gonçalves Vieira ${ }^{5}$

1 Mestre em Medicina Tropical (Microbiologia), Universidade Federal de Goiás 2 Doutoranda em Ciências Ambientais, Universidade Federal de Goiás

3 Mestre em Biologia da Relação Parasito-Hospedeiro, Universidade Federal de Goiás

4 Graduando do curso de Biotecnologia, Universidade Federal de Goiás

5 Professor Doutor do Departamento de Microbiologia, Imunologia, Parasitologia e Patologia do Instituto de Patologia Tropical e Saúde Pública da Universidade Federal de Goiás (jdgvieira62@gmail.com) Goiânia-Brasil

\section{Recebido em: 08/09/2015 - Aprovado em: 14/11/2015 - Publicado em: 01/12/2015} DOI: http://dx.doi.org/10.18677/Enciclopedia_Biosfera_2015_021

Endofíticos são micro-organismos que passam uma parte ou todo o ciclo de vida no interior de vegetais. Sob condições de estresse, tais como déficit hídrico, invasão por fitopatógenos ou contato com substâncias tóxicas, eles geram diversas biomoléculas que auxiliam na proteção vegetal. $O$ atual estudo visou isolar e avaliar o potencial enzimático e antimicrobiano de micro-organismos endofíticos de Hyptis suaveolens (L.) Poit., uma espécie vegetal amplamente empregada em fitoterapia brasileira. Um total de 39 isolados microbianos foram selecionados de diferentes partes da planta. Após identificação, constatou-se que a maior parte dos micro-organismos isolados eram bactérias pertencentes aos gêneros Pseudomonas sp. $(23,1 \%)$, Bacillus sp. (23,0\%), Streptomyces sp. (20,5\%), Alcaligenes sp. (17,9\%), Micrococcus sp. $(5,1 \%)$, Comamonas sp. (2,6\%), Acinetobacter sp. (2,6\%) e Staphylococcus sp. $(2,6 \%)$, e uma levedura do gênero Rhodotorula sp. (2,6\%). Pelo menos um tipo de ação de uma exoenzima (amilase, lipase, esterase, pectinase ou protease) foi observada para 25 isolados (64,1\%). Quanto a triagem da atividade antimicrobiana in vitro, verificou-se que 15 isolados (38,5\%) exibiram capacidade de inibir 0 crescimento de algum dos 16 micro-organismos-alvo, com destaque as amostras Pseudomonas aeruginosa MC 7B e Pseudomonas fluorescens MC 15, as quais apresentaram o maior grau de ação antibiótica contra 15 (93,8\%) e 9 (56,2\%) das cepas bacterianas indicadoras, respectivamente. Em conclusão, a pesquisa evidencia que a comunidade endofítica dessa planta medicinal exibe um profícuo potencial para a geração de enzimas de interesse industrial e antimicrobianos.

PALAVRAS-CHAVE: micro-organismos endofíticos, Hyptis suaveolens (L.) Poit., enzimas, atividade antibacteriana, bioprospecção. 


\title{
ISOLATION, IDENTIFICATION AND EVALUATION OF THE ENZYMATIC AND ANTIBACTERIAL ACTIVITIES OF ENDOPHYTIC MICROORGANISMS FROM Hyptis suaveolens (L.) Poit.
}

\begin{abstract}
Endophytic are microorganisms that spent part or all the life cycle inside vegetal tissues. Under stress conditions, as hydric deficit, phytopathogen invasion or contact with toxic substances, they generate diverse biomolecules that aid in the vegetal protection. The actual study aimed to isolate and evaluate the enzymatic and antimicrobial potential of endophytic microorganisms from Hyptis suaveolens (L.) Poit., a vegetal species broadly applied in the Brazilian phytotherapy. A total of 39 microbial isolates were selected from different parts of the plants. After the identification, it was found the most part of the isolated microorganisms were bacteria belonging to the genera Pseudomonas sp. (23,1\%), Bacillus sp. $(23,0 \%)$, Streptomyces sp. (20.5\%), Alcaligenes sp. (17,9\%), Micrococcus sp. $(5,1 \%)$, Comamonas sp. (2,6\%), Acinetobacter sp. (2,6\%) and Staphylococcus sp. (2,6\%), and a yeast from the genus Rhodotorula sp. (2.6\%). At least one type of a exoenzyme action (amylase, lipase, esterase, pectinase or protease) was observed for 25 isolates $(64,1 \%)$. Concerning the in vitro screening of the antimicrobial activity, it was observed 15 isolates $(38,5 \%)$ exhibited capacity to inhibit the growth of some of the 16 target microorganisms, especially the strains Pseudomonas aeruginosa MC 7B and Pseudomonas fluorescens MC 15, which presented the highest level of antibiotic action against $15(93,8 \%)$ and $9(56,2 \%)$ of the indicator bacterial strains, respectively. In conclusion, the study highlights the endophytic community from this medicinal plant exhibits a profitable potencial for the generation of enzymes of industrial interest and antimicrobials.
\end{abstract}

KEYWORDS: endophytic microorganisms, Hyptis suaveolens (L.) Poit., enzymes, antibacterial activity, bioprospecting.

\section{INTRODUÇÃO}

Endofíticos (do grego, "endon", dentro; "phyton", planta) são microorganismos que passam parte ou toda a vida colonizando tecidos vegetais (SCHULZ \& BOYLE, 2005; HARDOIM et al., 2015). A associação desses organismos com o vegetal é ubíqua, pode ser obrigatória ou facultativa, sem causar danos ao vegetal. De modo a manter essa relação simbiótica estável, endofíticos sintetizam vários compostos que promovem o crescimento das plantas e as auxiliam a melhor se adaptarem o ambiente (NAIR \& PADMAVATHY, 2014).

Endofíticos também são responsáveis pela geração de compostos com função de auxinas, impulsionando a produção e germinação de sementes e o desenvolvimento apical, e de metabólitos secundários, moléculas que ativam a resposta do sistema de estresse na planta hospedeira e acarreta em uma maior resistência a invasão por fitopatógenos. Dentre algumas das funções valiosas dessas bactérias e fungos, pode-se citar a remoção de contaminantes, solubilização de fosfato, assimilação de nitrogênio e fornecimento de vitaminas essenciais e outros micronutrientes para o vegetal. Alguns outros efeitos consequentes da colonização por esses micro-organismos também incluem o ajuste osmótico, regulação da função do estoma, alteração da morfologia das raízes, elevação da captação de minerais e modificações do acúmulo e metabolismo de nitrogênio (DUDEJA et al., 2012). Há aproximadamente 300.000 espécies de plantas no planeta, e todas, sem exceção, são hospedeiras de um ou mais endofíticos, estando 
presentes ao longo de toda a estrutura do vegetal e em diferentes níveis populacionais (STROBEL \& DAISY, 2003; STEPNIEWSKA \& KUZNIAR, 2013).

Enzimas são potenciais biocatalisadores de um amplo número de reações, sendo amplamente aplicadas em inúmeros processos de significância industrial, médica e biotecnológica, como aditivos detergentes, na geração de produtos farmacêuticos e terapêuticos, agroquímicos, alimentos, detergentes e tecidos, e na biorremediação e reutilização de rejeitos industriais. Particularmente, enzimas microbianas são mais ativas e estáveis que as derivadas de plantas e animais. Além dessas vantagens, os micro-organismos representam uma fonte alternativa atraente de enzimas uma vez que podem ser obtidas em altas concentrações em um curto período de tempo por fermentação, a diversidade química e suscetibilidade a manipulação gênica, o que é vantajoso, considerando a atual demanda dessas proteínas frente a crescente necessidade de soluções sustentáveis (ANBU et al., 2013; ADRIO \& DEMAIN, 2014).

Sabe-se que endofíticos são prolíficos produtores de exoenzimas que contribuem para o catabolismo de vários biopolímeros de maior complexidade, o que se deve a modo de nutrição absortiva desses organismos e da variedade de substratos que aproveitam para o crescimento, gerando celulases, quitinases, amilases, lipases, proteases e etc. (SURYANARAYANAN et al., 2012). A liberação extracelular dessas enzimas também está relacionada com o processo de estabelecimento do endofítico no vegetal, via hidrólise de componentes da parede celular vegetal, e como um mecanismo de defender a planta hospedeira de invasores microbianos (CORRÊA et al., 2014; ZHOU et al., 2014).

A resistência aos agentes antimicrobianos por patógenos humanos e fitopatógenos está aumentando em uma proporção alarmante. Os endofíticos constituem um nicho particularmente rico de metabólitos secundários com ação antibiótica e herbicida, incluindo alcaloides, peptídeos, terpenóides, quinonas, flavonoides, compostos alifáticos e fenóis, e já foram isoladas de organismos residentes em plantas medicinais, grãos, e espécies vegetais de ambientes extremos. Assim, esses micro-organismos formam uma opção segura para a procura de produtos farmacologicamente bioativos, considerando que ainda podem ser manipulados nos aspectos físico-químicos e genético para elevar a síntese das biomoléculas de interesse e gerar análogos inéditos de compostos já existentes. $\mathrm{A}$ origem desses metabólitos se deve estritamente a co-evolução da simbiose plantamicro-organismo, a qual ainda não é plenamente compreendida. A investigação por esses produtos naturais derivados de endofíticos é válida, já que há muito a ser explorado quanto ao possível potencial terapêutico dessas moléculas. (OWEN \& HUNDLEY, 2004; STROBEL, 2006; YU et al., 2010; GUTIERREZ et al., 2012).

Hyptis suaveolens (L.) Poit. (Lamieaceae), popularmente conhecida no Brasil como "malva-do-campo", "bambuzal", "erva canudo", ou "tapera velha", é uma espécie vegetal nativa das Américas, encontrada em solos drasticamente alterados pela ação humana e distribuída em regiões tropicais e subtropicais, podendo se desenvolver também em condições de clima semiárido. Essa erva é empregada na medicina popular no tratamento de infecções respiratórias e gastrointestinais, indigestão, resfriados, dores, espasmos, doenças dermatológicas e em úlceras gástricas e em condições envolvendo exacerbação inflamatória (MARTINS \& POLO, 2009; JESUS et al., 2013; PADALIA et al., 2015). Extratos e óleos essenciais derivados dessa planta exibem uma ampla gama de atividades biológicas, com destaque a antioxidante, anti-inflamatória, antimicrobiana, anti-helmíntica e até mesmo uma ótima ação repelente a mosquitos (ABAGLI et al., 2012; NGOZI et al., 
2014). Recentemente, vários compostos ativos de Hyptis suaveolens (L.) Poit. vêm sendo caracterizados, especialmente da classe dos diterpenos, como o isolamento do suaveolol, a substância responsável pelo acentuado e já conhecido efeito gastroprotetor dessa espécie vegetal (VERA-ARZAVE et al., 2012), e do relacionado ácido suaveólico, o qual possui propriedades fitotóxicas (ISLAM et al., 2014).

Considerando o potencial vasto de aplicações desses micro-organismos, e de modo a acrescentar as pesquisas na área, o objetivo do presente estudo foi o isolamento, identificação e avaliação da capacidade de produção de enzimas de interesse biotecnológico e de compostos com atividade antibacteriana de endofíticos de Hyptis suaveolens (L.) Poit., uma planta medicinal comumente empregada na medicina popular goiana.

\section{MATERIAL E METODOS}

\section{Isolamento de micro-organismos endofíticos}

Amostras de caule, folha e pecíolo de Hyptis suaveolens (L.) Poit. foram coletadas na horta medicinal da Faculdade de Farmácia (FF) da Universidade Federal de Goiás (UFG) e transportadas imediatamente ao Laboratório de Microbiologia Ambiental e Biotecnologia (LAMAB) Instituto de Patologia Tropical e Saúde Pública da UFG. O material foi lavado com água corrente e sabão e, após secagem sobre papel toalha a temperatura ambiente, submetido a desinfecção superficial de acordo com a metodologia proposta por ARAÚJO et al., (2002). A sequência de desinfecção foi a seguinte: etanol $70 \%(\mathrm{v} / \mathrm{v})$ por 1 minuto; hipoclorito de sódio a 2,0\% (v/v), por 4 minutos; três lavagens em água destilada esterilizada; banho de ultrassom $(40 \mathrm{kHz})$ por 10 minutos; duas lavagens com água destilada esterilizada, novo banho de ultrassom por 10 minutos; três lavagens com água destilada esterilizada; tratamento com etanol $70 \%$ por 30 segundos, seguido de duas lavagens com água destilada esterilizada. $\mathrm{O}$ controle desse processo foi realizado inoculando três alíquotas de $1,0 \mathrm{~mL}$ da última água de lavagem das amostras em tubos contendo caldo nutriente e caldo $\mathrm{BHI}$ e incubadas a $30^{\circ} \mathrm{C}$, por 72 horas; após esse período essas amostras foram inoculadas em placas de Petri contendo ágar nutriente e incubadas a ${ }^{\circ} 0^{\circ} \mathrm{C}$, por 48 horas. A ausên cia de crescimento microbiano foi indicativa da eficiência da desinfecção.

Para o isolamento dos micro-organismos endofíticos foram utilizadas as técnicas de fragmentação e maceração. A fragmentação foi realizada cortando-se as amostras previamente desinfetadas com o auxílio de um bisturi esterilizado, obtendo fragmentos de $1,0 \mathrm{~cm}^{2}$. Os fragmentos foram então macerados em $9,0 \mathrm{~mL}$ de caldo $\mathrm{BHI}$ e transferidos para Erlenmeyer de $125 \mathrm{~mL}$; e incubados a $30^{\circ} \mathrm{C}, 150 \mathrm{rpm}$, por duas horas. Os fragmentos e $100 \mu \mathrm{L}$ da suspensão do macerado foram semeados em placas de Petri individualmente. Foram empregados para o isolamento de bactérias: ágar nutriente, TSA (do inglês, Tryptone Soya Agar), Meio de King, ágar nutriente com água peptonada. O ágar amido-caseína e o ágar ISP-2 (extrato de malte-extrato de levedura) acrescido de $1,0 \%$ de amido $(\mathrm{m} / \mathrm{v})$ foram utilizados para 0 isolamento de actinobactérias. Foram acrescidos de nistatina e cicloheximida (50 $\mu \mathrm{g} / \mathrm{mL}$ ) a todos os meios para a inibição do crescimento de fungos. Os meios de cultivo para 0 isolamento de fungos consistiram em ágar batata-dextrose (BDA) acidificado e meio Sabourad-dextrose, todos suplementados com penicilina (75 $\mu \mathrm{g} / \mathrm{mL})$, tetraciclina $(50 \mu \mathrm{g} / \mathrm{mL})$ e cloranfenicol $(100 \mu \mathrm{g} / \mathrm{mL})$ (ARAÚJO et al., 2002).

A incubação das placas de Petri foi a $30^{\circ} \mathrm{C}$ durante um período de 30 dias. $\mathrm{O}$ material foi diariamente monitorado para o isolamento e purificação dos microorganismos. Os micro-organismos crescidos foram purificados pela técnica de ENCICLOPÉDIA BIOSFERA, Centro Científico Conhecer - Goiânia, v.11 n.22; p3039 
esgotamento em meio sólido, em até cinco vezes. Após a purificação as bactérias foram mantidas em ágar nutriente, as actinobactérias em ágar ISP-2 com 1,0\% de amido e os fungos em BDA acidificado, sendo armazenados em geladeira a $4^{\circ} \mathrm{C}$. Os isolados também foram preservados em estoques de glicerol a $50 \%(\mathrm{v} / \mathrm{v})$ em freezer a $-20^{\circ} \mathrm{C}$.

\section{Identificação dos micro-organismos endofíticos}

As bactérias isoladas foram inicialmente caracterizadas pelo aspecto das colônias e a morfologia celular pela coloração de Gram. A identificação das espécies dos micro-organismos isolados foi realizada utilizando o sistema automatizado MicroScan-4 da Dade Bering, o qual consiste de placas de microtitulação descartáveis, de tamanho padronizado, nas quais estão incluídos até 32 substratos reativos. Os microtubos foram inoculados com uma suspensão dos microorganismos em estudo e incubados a $3^{\circ} \mathrm{C}$ durante 15 a $18 \mathrm{~h}$. Os painéis inicialmente foram interpretados visualmente e, em seguida, foi utilizado um leitor automático de placas do aparelho. Através de um software que compara padrões de reações com um programa interno de probabilidade, os isolados foram identificados.

As actinobactérias foram identificadas por análises morfológica e químicocelular, pela determinação do ácido diaminopimélico (DAP). A caracterização morfológica foi realizada de acordo com o descrito por SHIRLING \& GOTTLIEB, 1966. Alíquotas de $5,0 \mu \mathrm{L}$ das culturas de isoladas foram inoculadas sobre a superfície do Ágar ISP-2, espalhadas com alça microbiológica e incubadas a $30^{\circ} \mathrm{C}$ por 21 dias. As observações das características morfológicas macroscópicas foram feitas com 7, 14 e 21 dias de cultivo. As características microscópicas foram feitas inserindo-se lamínulas (esterilizadas) num ângulo de aproximadamente 45 sobre a superfície do ágar, com observação consecutiva ao microscópio óptico de luz na objetiva de imersão após 21 dias de crescimento.

A análise do DAP das actinobactérias endofíticas foi realizada conforme a técnica de hidrólise de células totais de BECKER et al., 1964. Os esporos dos isolados foram inoculados em Erlenmeyers de $250 \mathrm{~mL}$ contendo $50 \mathrm{~mL}$ de caldo ISP-2 e incubadas sob agitação a $30^{\circ} \mathrm{C}$, a 180 rpm po 7 dias. A porção micelial foi filtrada em filtro de papel (Whatman $\mathrm{n}-1$ ) e lavadas cinco vezes com água destilada esterilizada. A massa celular obtida foi seca em estufa a $60-70{ }^{\circ} \mathrm{C}$ até peso constante e armazenada em tubos tipo Eppendorf a $-20^{\circ} \mathrm{C}$ até a utilização. Uma massa seca de $30-40 \mathrm{mg}$ de células foi hidrolisada em tubos com tampa rosqueável de $13 \times 100$ $\mathrm{mm}$ com $1,0 \mathrm{~mL}$ de $\mathrm{HCl}$ a $6 \mathrm{M}$ a $100^{\circ} \mathrm{C}$ por 20 horas. Após esse período, os hidrolisados celulares foram filtrados em papel de filtro (Whatman $\mathrm{n}^{\circ} 1$ ) e o resíduo lavado com água destilada esterilizada. A fração líquida resultante foi concentrada em evaporador rotativo a $50^{\circ} \mathrm{C}$, para a remoção do excesso de $\mathrm{HCl}$ e o resíduo ressuspenso em $400 \mu \mathrm{L}$ de água destilada esterilizada. Um total de 2,0 a 4,0 $\mu \mathrm{L}$ da suspensão dos hidrolisados foram aplicados em placas de TLC Merck 5716 (20x18cm). Paralelamente, foram aplicados também entre 2,0 a 4,0 $\mu \mathrm{L}$ de um hidrolisado de Streptomyces DAUFPE 5622 como padrão de L-DAP e Nocardia asteroides como padrão de meso-DAP. A cromatografia foi desenvolvida com 0 sistema solvente metanol/H2O/HCl 10N/piridina, na proporção 80: 17,5: 2,5: 10 (v/v), e a revelação realizada borrifando uma solução de ninhidrina a 0,1\% em acetona sobre a placa, seguida de aquecimento a $100^{\circ} \mathrm{C}$ por 5 minutos para visualização dos isômeros de DAP.

O fungo endofítico isolado foi inicialmente caracterizado pelas características macro e microscópicas da colônia e a morfologia celular pela coloração de azul-de- 
lactofenol (azul-de-algodão). A identificação da espécie foi realizada com o sistema automatizado MicroScan-4 da Dade Bering, da mesma forma citada anteriormente para bactérias.

\section{Avaliação da atividade enzimática dos isolados microbianos endofíticos}

Foi analisada a capacidade de síntese das seguintes enzimas de interesse biotecnológico: amilase, lipase, esterase, pectinase, protease e celulase. A determinação da atividade enzimática foi realizada inicialmente crescendo os isolados em caldo $\mathrm{BHI}$ a $30^{\circ} \mathrm{C}$ por 24 horas. Após esse tempo, alíquotas de $100 \mu \mathrm{L}$ foram inoculadas com o auxílio de um inoculador de Steers em meios de cultura sólidos específicos para cada enzima. O Índice Enzimático (IE) foi determinado pelo método de HANKIN \& ANAGNOSTAKIS (1975), pelo cálculo da relação entre o diâmetro médio do halo de degradação e o diâmetro médio da colônia após 96 horas de incubação. Foram realizadas cinco repetições para cada enzima e microorganismo testado. Os resultados foram analisados estatisticamente pelo teste de análise de variância comparados pelo teste de $t$, com um nível de tolerância de $95 \%$, utilizando o programa Statistica versão 10.0 (StatSoft@)).

Para a determinação da produção de amilases, foi usado o método descrito por HANKIN \& ANAGNOSTAKISS (1975). O meio usado foi o ágar nutriente contendo $0,2 \%$ de amido solúvel ( $\mathrm{pH} 6,0$ ). Após 96 horas de incubação a $30^{\circ} \mathrm{C}$, as placas foram reveladas com vapores de iodo metálico. A ação amilolítica foi visualizada pela presença de halo claro ao redor da colônia.

A atividade celulolítica foi averiguada empregando-se o método sugerido por STAMFORD et al., (1998). O meio de triagem enzimática consistiu de (g/L): $\mathrm{KH}_{2} \mathrm{PO}_{4}$ 7,0; $\mathrm{MgSO}_{4} .7 \mathrm{H}_{2} \mathrm{O} 0,1 ;\left(\mathrm{NH}_{4}\right)_{2} \mathrm{SO}_{4} 1,0$; extrato de levedura 0,6; Avicel 10; ágar-ágar $15,0, \mathrm{pH} 7,2 \pm 0,2$. Depois de um período de incubação de 96 horas a $30^{\circ} \mathrm{C}$, as placas foram incubadas a $50^{\circ} \mathrm{C}$ por mais de 12 horas para melhor visualização do halo claro ao redor das colônias.

Foram utilizadas duas metodologias para determinação da atividade proteolítica. Na primeira foi aplicado o meio de cultura contendo $(\mathrm{g} / \mathrm{L})$ : caldo nutriente 8,0; glucose 1,0; leite desnatado 15,0 mL; ágar-ágar 18,0. Seguidamente a 96 horas de incubação a $30^{\circ} \mathrm{C}$, as placas foram reveladas com solução de ácido acético a $5,0 \%$ (v/v) (VIEIRA, 1999). A presença de halo claro ao redor da colônia foi indicativa de positividade. Na segunda metodologia foi determinada a hidrólise da gelatina segundo SMIBERT \& KRIEG (1994). Nesta metodologia foi empregado o ágar gelatina de Frazier, constituído de ágar nutriente adicionado de $4,0 \mathrm{~g} / \mathrm{L}$ de gelatina bacteriológica. As colônias foram incubadas por 72 horas a $30^{\circ} \mathrm{C}$. Após esse tempo, as placas foram recobertas pelo revelador de Frazier $\left(\mathrm{HCl} 20,0 \mathrm{~mL} ; \mathrm{HgCl}_{2} 15,0 \mathrm{~g} \mathrm{em}\right.$ $100 \mathrm{~mL}$ de água destilada). A presença de halo claro ao redor da colônia evidenciou resultado positivo.

O método proposto por SIERRA (1957) foi aplicado para análise da geração de lipase e esterase pelos isolados endofíticos. Foi empregado o meio de cultivo constituído de (g/L): Bacto peptona 10,0; $\mathrm{NaCl} 5,0 ; \mathrm{CaCl}_{2} . \mathrm{H}_{2} \mathrm{O}$ 0,1; ágar-ágar 18,0, $\mathrm{pH} 7,2 \pm 0,2$. Após a esterilização, o meio foi suplementado com 1,0 $\mathrm{mL}$ de Tween 80 e Tween 20 a uma concentração final de $1,0 \%(\mathrm{v} / \mathrm{v})$ para determinação das atividades lipolítica e esterásica, respectivamente. As placas foram incubadas por 96 horas a $30^{\circ} \mathrm{C}$, e a liberação dessas enzimas foi avaliada pelo aparecimento de uma região opaca ao redor da colônia.

A metodologia descrita por HANKIN et al., (1971) foi adotada para determinação da atividade pectinolítica. Os isolados foram inoculados em placas de 
Petri contendo meio de cultivo formado de (g/L): Solução A: $\mathrm{KH}_{2} \mathrm{PO}_{4} 4,0 ; \mathrm{Na}_{2} \mathrm{HPO}_{4}$ 6,0; $\mathrm{H}_{2} \mathrm{O} 200 \mathrm{~mL}$; Solução B: pectina 5,0; $\mathrm{H}_{2} \mathrm{O} 200 \mathrm{~mL}$; Solução C: $\left(\mathrm{NH}_{4}\right)_{2} \mathrm{SO}_{4} 2,0$; $\mathrm{FeSO}_{4} \cdot 7 \mathrm{H}_{2} \mathrm{O} 0,001 ; \mathrm{MgSO}_{4} .7 \mathrm{H}_{2} \mathrm{O} 0,2 ; \mathrm{CaCl}_{2} 0,001$; extrato de levedura 1,$0 ; \mathrm{pH} 7,2 \pm$ 0,2 . As três soluções foram esterilizadas separadamente e reunidas no momento da utilização. Após 96 horas de incubação a $30^{\circ} \mathrm{C}$, as placas foram recobertas com uma solução de brometo de hexadeciltrimetil amônio (CTAB) a 1,0\% (m/v) e incubadas a temperatura ambiente por uma hora. As placas foram então lavadas com água destilada esterilizada e a degradação da pectina constatada pela presença de zona clara envolvendo a colônia.

\section{Avaliação da atividade antibacteriana dos isolados microbianos endofíticos}

A atividade antibacteriana dos micro-organismos endofíticos foi avaliada qualitativamente pelo método de difusão em ágar de Kirby-Bauer (BAUER et al., 1966), em ágar de Mueller-Hinton. Foram utilizadas as seguintes cepas bacterianas indicadoras: bactérias gram-positivas: Bacillus subtilis ATCC 6633, Micrococcus luteus ATCC 9341, Staphylococcus aureus ATCC 29737, Bacillus cereus ATCC 14579, Rhodococcus equi CCT 0541, Staphylococcus epidermidis ATCC 1488, Corynebacterium glutamicum e bactérias gram-negativas: Enterobacter aerogenes ATCC 13048, Salmonella typhimurium ATCC 14028, Pseudomonas aeruginosa ATCC 9027, Serratia marcescens ATCC 14756, Escherichia coli ATCC 25922, Salmonella choleraesuis ATCC 10708, Agrobacterium tumefaciens A6, Agrobacterium tumefaciens ATCC 33970/C58, Agrobacterium tumefaciens Ach5.

Para a determinação da presença de atividade antimicrobiana das actinobactérias isoladas, $10 \mu \mathrm{L}$ de uma suspensão de esporos dos isolados foram inoculadas em toda a superfície do ágar ISP-2 e incubadas a $30^{\circ} \mathrm{C}$ por 15 dias. Consecutivamente a esse período, discos de $7,0 \mathrm{~mm}$ do ágar foram cortados e colocados sobre placas de Petri contendo meio ágar Mueller-Hinton, previamente semeadas com as cepas indicadoras cuja concentração foi ajustada para a escala 0,5 de MacFarland. As placas foram incubadas a $30^{\circ} \mathrm{C}$ por 24 horas e 0 aparecimento de zonas de inibição ao redor do cilindro de ágar com diâmetro superior a $10 \mathrm{~cm}$ indicou a presença da atividade antimicrobiana.

A ação antibacteriana para as demais bactérias foi conduzida pelo método de sobrecamada, utilizando-se o meio 523 de Kado e Heskett (KADO \& HESKETT, 1970). Alíquotas de $10 \mu \mathrm{L}$ das bactérias isoladas, previamente crescidas em caldo nutriente, foram inoculadas em placas de Petri contendo o meio 523 e incubadas a $30^{\circ} \mathrm{C}$ por 48 horas. Após este período as placas foram expostas à luz UV $(\lambda=$ $254 \mathrm{~nm}$ ) por 30 minutos para inativação do crescimento bacteriano. Em seguida as placas receberam uma sobrecamada com 5,0 $\mathrm{mL}$ de ágar $\mathrm{BHI}$ semi-sólido $(0,6 \%$ de ágar bacteriológico tipo I) contendo uma suspensão das bactérias indicadoras padronizadas para metade da turbidez do tubo $\mathrm{n}^{0} 1$ da escala de MacFarland. As placas foram novamente incubadas a $30^{\circ} \mathrm{C}$ e os halos de inibição de crescimento dos indicadores foram determinados após 24, 48, 72, 96 e 120 horas de crescimento (ROMEIRO, 1989).

\section{RESULTADOS E DISCUSSÃO}

\section{Isolamento e identificação dos micro-organismos endofíticos isolados}

Foram isolados 39 micro-organismos dos diferentes órgãos vegetativos (caule, folha e pecíolo) de Hyptis suaveolens (L.) Poit. Após a identificação morfológica e bioquímica, os micro-organismos foram agrupados em oito gêneros de bactérias e um de levedura. Dos isolados, ocorreu um predomínio de bactérias dos 
gêneros Pseudomonas sp. (23,1\%), Bacillus sp. (23,0\%), Streptomyces sp. (20,5\%), Alcaligenes sp. (17,9\%), Micrococcus sp. (5,1\%), Comamonas sp. $(2,6 \%)$, Acinetobacter sp. (2,6\%) e Staphylococcus sp. $(2,6 \%)$, e o fungo leveduriforme Rhodotorula sp. (2,6\%) (Tabela 1). Depois da análise do perfil da atividade enzimática, quatro isolados foram reagrupados, um como Pseudomonas aeruginosa, um como Bacillus sp., e dois como Alcaligenes sp.

Existem poucos relatos na literatura de pesquisas de micro-organismos endofíticos de plantas do gênero Hyptis. VITORINO et al., (2012a) efetuaram o isolamento e caracterização de bactérias e fungos em dois tipos de raízes de Hyptis marrubioides Epling. As bactérias eram, em sua maior parte, bacilos gram-positivos e catalase-positivos, e a maioria dos fungos desenvolviam micélios esporulantes. Em um estudo consecutivo, VITORINO et al., (2012b) avaliaram a produção de ácido indolacético (AIA) e capacidade de solubilização de fosfato de cálcio e ferro por essas mesmas cepas previamente isoladas, com várias amostras se apresentando como potenciais produtoras desses fatores de crescimento vegetal, assim como no aproveitamento das fontes de fosfato.

Com base nessa prospecção inicial, VITORINO et al., (2013) efetuaram testes de inoculação in vito em explantes de Hyptis marrubioides Epling., analisando o comportamento dos isolados microbianos na planta com a concomitante identificação dos metabólitos produzidos pelos mesmos. Os autores observaram que certos isolados não exibiam endofitismo e, sim parasitismo em certo ponto dos testes, e que os mesmos empregados como elicitores induzem diferentes respostas metabólicas nos propágulos, dependendo das condições experimentais.

TABELA 1 Ocorrência e identificação de micro-organismos isolados de Hyptis suaveolens (L.) Poit.

\begin{tabular}{lcc}
\hline \multicolumn{1}{c}{ Micro-organismos isolados } & Número de isolados & Ocorrências (\%) \\
\hline Pseudomonas fluorescens & 04 & 10,3 \\
Pseudomonas stutzeri & 02 & 5,1 \\
Pseudomonas aeruginosa & 02 & 5,1 \\
Pseudomonas sp. & 01 & 2,6 \\
Comamonas acidovirans & 01 & 2.6 \\
Alcaligenes sp. & 07 & 17,9 \\
Acinetobacter lwoffii & 01 & 2,6 \\
Staphylococcus warneri & 01 & 2,6 \\
Micrococcus sp. & 02 & 5,1 \\
Bacillus sp. & 09 & 23,0 \\
Streptomyces sp. & 08 & 20,5 \\
Rhodotorula sp. & 01 & 2,6 \\
\hline Total & $\mathbf{3 9}$ & $\mathbf{1 0 0}$ \\
\hline
\end{tabular}

Atividade enzimática dos micro-organismos endofíticos isolados

Os resultados da triagem da produção de enzimas estão apresentados na Tabela 2. Com exceção das amostras Streptomyces MC 31 e MC 41 e da levedura Rhodotorula sp. (dados não mostrados), os demais micro-organismos endofíticos apresentaram a capacidade de produzir pelo menos uma das enzimas prospectadas, pela metodologia de obtenção do IE. Esse índice é uma ferramenta prática e rápida de seleção e comparação da síntese de diferentes enzimas por diferentes micro-organismos, uma vez que relaciona o diâmetro do halo de degradação e o diâmetro da colônia do micro-organismo estudado. Valores de IE maiores que 1.0 são sugestivos da excreção das enzimas. Essa razão fornece uma noção qualitativa importante da atividade enzimática microbiana (LIN et al., 1991; FUNGARO \& MARCCHERONI, 2002). 
TABELA 2 Atividades enzimáticas dos micro-organismos endofíticos isolados de Hyptis suaveolens (L.) Poit ${ }^{1}$.

\begin{tabular}{|c|c|c|c|c|c|c|c|}
\hline \multirow[b]{2}{*}{ Micro-organismos isolados } & \multirow[b]{2}{*}{$\begin{array}{l}\text { Identificação do isolado na } \\
\text { bacterioteca do laboratório }\end{array}$} & \multicolumn{6}{|c|}{ Índice Enzimático (IE) ${ }^{2}$} \\
\hline & & Amilase & $\begin{array}{c}\text { Esterase } \\
\text { (Tween 20) }\end{array}$ & $\begin{array}{c}\text { Lipase } \\
\text { (Tween 80) }\end{array}$ & $\begin{array}{c}\text { Proteolítico } \\
\text { (Caseína) }\end{array}$ & $\begin{array}{c}\text { Proteolítico } \\
\text { (Gelatina) }\end{array}$ & Pectinolítica \\
\hline Pseudomonas fluorescens & MC 5 & 0.0 & $1.3^{c}$ & $1.2^{d}$ & $3.2^{c}$ & $1.8^{\mathrm{g}}$ & 0.0 \\
\hline Pseudomonas fluorescens & MC 15 & 0.0 & 0.0 & $1.3^{d}$ & $2.3^{\mathrm{e}}$ & $2.4^{\text {ef }}$ & 0.0 \\
\hline Pseudomonas stutzeri & $\mathrm{MC} 2 \mathrm{~B}$ & 0.0 & 0.0 & $1.2^{d}$ & $3.3^{c}$ & $2.1^{f}$ & 0.0 \\
\hline Pseudomonas aeruginosa & MC 7B & 0.0 & 0.0 & 0.0 & $2.5^{\mathrm{de}}$ & $2.1^{f}$ & 0.0 \\
\hline Pseudomonas acidovirans & MC 5B & 0.0 & $1.7^{\mathrm{b}}$ & 0.0 & 0.0 & 0.0 & 0.0 \\
\hline Alcaligenes sp. & MC 2D & 0.0 & $1.4^{\mathrm{C}}$ & $2.7^{\mathrm{ab}}$ & $4.4^{a}$ & $3.6^{b c}$ & 0.0 \\
\hline Alcaligenes sp. & MC 9B & $3.5^{\mathrm{a}}$ & $2.4^{\mathrm{a}}$ & $2.0^{c}$ & 0.0 & 0.0 & 0.0 \\
\hline Alcaligenes sp. & MC 9D & 0.0 & $2.5^{a}$ & $2.9^{a}$ & $2.7^{d}$ & $3.1^{d}$ & 0.0 \\
\hline Alcaligenes sp. & MC 10 & 0.0 & $1.5^{b c}$ & 0.0 & $3.8^{b}$ & $3.9^{b}$ & 0.0 \\
\hline Acinetobacter Iwoffii & MC 29 & 0.0 & $1.5^{b c}$ & 0.0 & 0.0 & 0.0 & 0.0 \\
\hline Micrococcus sp. & MC 21 & 0.0 & $2.5^{\mathrm{a}}$ & 0.0 & 0.0 & 0.0 & 0.0 \\
\hline Micrococcus sp. & MC 38 & $1.6^{b}$ & 0.0 & $2.5^{b c}$ & $3.3^{e}$ & 0.0 & 0.0 \\
\hline Bacillus sp. & $M C 1^{a}$ & $2.0^{b c}$ & 0.0 & 0.0 & 0.0 & 0.0 & 0.0 \\
\hline Bacillus sp. & $M C 1 B$ & 0.0 & 0.0 & 0.0 & $2.8^{d}$ & $3.4^{\text {ed }}$ & 0.0 \\
\hline Bacillus sp. & MC 3 & 0.0 & 0.0 & 0.0 & $3.5^{b c}$ & 0.0 & 0.0 \\
\hline Bacillus sp. & $\mathrm{MC} 8 \mathrm{~B}$ & $1.8^{\mathrm{c}}$ & $1.3^{c}$ & 0.0 & $3.7^{b}$ & $3.0^{d}$ & 0.0 \\
\hline Bacillus sp. & MC 22 & $2.8^{a b}$ & 0.0 & 0.0 & $2.0^{\text {ef }}$ & 0.0 & 0.0 \\
\hline Bacillus sp. & MC 23 & $2.2^{b}$ & 0.0 & 0.0 & $2.2^{\mathrm{e}}$ & $2.5^{\mathrm{e}}$ & 0.0 \\
\hline Bacillus sp. & MC 32 & $1.6^{\mathrm{c}}$ & $1.7^{\mathrm{b}}$ & 0.0 & $1.6^{\mathrm{g}}$ & $1.6^{\mathrm{g}}$ & 0.0 \\
\hline Streptomyces sp. & MC 18 & $3.1^{\mathrm{a}}$ & $2.5^{\mathrm{a}}$ & $1.3^{d}$ & $1.5^{\mathrm{g}}$ & $2.9^{\mathrm{de}}$ & 3.4 \\
\hline Streptomyces sp. & MC 30 & $1.9^{\mathrm{C}}$ & 0.0 & 0.0 & 0.0 & 0.0 & 0.0 \\
\hline Streptomyces sp. & MC 38 & 0.0 & $2.2^{a b}$ & 0.0 & $1.9^{f g}$ & 0.0 & 0.0 \\
\hline Streptomyces sp. & MC 43 & 0.0 & 0.0 & 0.0 & $2.3^{\mathrm{e}}$ & 0.0 & 0.0 \\
\hline Streptomyces sp. & MC 44 & $2.3^{b}$ & 0.0 & 0.0 & 0.0 & 0.0 & 0.0 \\
\hline Streptomyces sp. & MC 45 & $2.9^{a b}$ & $1.3^{c}$ & 0.0 & $3.8^{b}$ & $4.7^{\mathrm{a}}$ & 0.0 \\
\hline
\end{tabular}

${ }^{1}$ Média de cinco repetições. As médias seguidas de mesma letra não diferem entre si (teste t de Student, $\left.p<0,05\right)$.

${ }^{2} \mathrm{O}$ IE representa a razão entre diâmetro do halo de degradação e o diâmetro da colônia microbiana. 
Os isolados Alcaligenes sp. MC 9B, Micrococcus sp. MC 38, Bacillus sp. MC 1A, MC 8B, MC 22, MC 23, MC 32, Streptomyces sp. MC 18, MC 30, MC 44, MC 45 exibiram ação amilolítica, correspondendo a $28,2 \%$ dos isolados. Observa-se que os isolados Alcaligenes sp. MC 9B e Streptomyces sp. MC 18 apresentam uma diferença significativa ao nível de $\mathrm{p}<0,05$ para 0 teste $t$ de Student quando comparados com os outros isolados quanto a atividade dessa enzima. Amilases possuem uma grande importância de aplicação biotecnológica, nas indústrias de alimentos, fermentação, têxtil e de papel, especialmente nos processos de liquefação e sacarificação (RANA et al., 2013). Espécies de Streptomyces são conhecidos produtores de uma variedade de enzimas hidrolíticas de amido, várias de fundamental aplicabilidade na indústria (KASHIWAGI et al., 2014). A amilase em Alcaligenes é raramente relatada, entretanto, RUSENDI \& SHEPPARD (1995) propõem a hidrólise enzimática do amido e a sua posterior utilização para a produção de polihidroxibutirato (PHB) por Alcaligenes sp., o que sugere que o isolado Alcaligenes sp. MC 9B possua potencialidades para a realização desta transformação em uma única etapa.

A geração de esterase foi verificada para os isolados Pseudomonas fluorescens MC 5A, Comamonas acidovirans MC 5B, Alcaligenes sp. MC 2D, MC 9B, MC 9D e MC 10, Acinetobacter sp. MC 2D, MC 9B, MC 9D e MC 10, Acinetobacter Iwoffii MC 29, Micrococcus sp. MC 21, Bacillus sp. MC 8B e MC 32, Streptomyces sp. MC 18, MC 38 e MC 45, equivalendo a um total de $33,3 \%$ dos micro-organismos isolados da planta medicinal. Os isolados Alcaligenes sp. MC $9 \mathrm{~B}$ e MC 9D, Micrococcus sp. MC 21, Streptomyces sp. MC 18 demonstraram uma diferença significativa ao nível de $\mathrm{p}<0,05$ para o teste $t$ de Student com relação às demais amostras endofíticas para a atividade esterásica.

A atividade lipolítica foi observada para os isolados Pseudomonas fluorescens MC 5A e MC 15, Pseudomonas stutzeri MC 2B, Alcaligenes sp. MC 2D, MC 9B e MC 9D, Micrococcus sp. MC 38 e Streptomyces sp. MC18, representando $20,5 \%$ dos isolados. Os isolados Alcaligenes sp. MC 2D e MC 9D e Micrococcus sp. MC 38 apresentaram diferença significativa ao nível de $p<0,05$ para o teste $t$ de Student em comparação às outras cepas recuperadas para a produção de lipases.

Há um especial interesse de emprego de lipases e esterases de origem microbiana para o processamento de óleos de gorduras na indústria farmacêutica, alimentícia e de papel, para biorremediação e na síntese de compostos opticamente puros (BORNSCHEUER, 2002; VERMA et al., 2012). Os isolados de Alcaligenes sp. obtidos possuem pelo menos uma das atividades (esterase e/ou lipase) sugerindo o seu emprego potencial em processos biotecnológico em conjunto com os demais isolados com estas atividades. MITSUKURA et al., (2010) verificaram uma excelente estereoseletividade e uma alta atividade frente a vários substratos de uma esterase purificada de Alcaligenes sp., revelando a funcionalidade de uma enzima microbiana ainda não manipulada.

Foram empregadas duas metodologias para a determinação da atividade proteolítica (hidrólise da caseína e da gelatina). Foi constatado que 46,1\% e 33,3\% dos isolados exibiram capacidade de hidrolisar caseína e gelatina, respectivamente. Os isolados Alcaligenes sp. MC 2D e MC 10, Bacillus sp. MC 8B e Streptomyces sp. MC 45 apresentaram diferença significativa ao nível de $\mathrm{p}<0,05$ para o teste $t$ de Student quando comparados com os outros isolados para a degradação de caseína. Apenas o isolado Streptomyces sp. MC 45 exibiu diferença significativa ao nível de $p$ $<0,05$ para o teste $t$ de Student em relação aos demais para a hidrólise de gelatina. Protases bacterianas tem especial relevância comercial como detergentes 
enzimáticos, sendo sua propriedade básica aproveitada para a geração de hidrolisados proteicos de alto valor nutricional (GUPTA et al., 2002). Bactérias do gênero Bacillus estão entre as principais fontes dessas enzimas, com destaque a Bacillus subtilis (PANT et al., 2015). As proteases de Alcaligenes são importantes para o tratamento (pelação) de couro e rejeitos de curtumes (THANGAM \& RAJKUMAR, 2000). Proteases derivadas de actinobactérias não recebem tanta atenção quanto as derivadas de outras bactérias. Todavia, micro-organismos do gênero Streptomyces se destacam quanto a síntese dessas enzimas, uma vez que eles as liberam em meio extracelular, o que é geralmente considerado como seguro quando aplicadas na administração de drogas e nutrientes (GHORBEL et al., 2014).

A atividade pectinolítica foi vista somente para o isolado Streptomyces sp. MC 18. A atividade celulolítica não foi observada nos micro-organismos isolados. Pectinases são empregadas principalmente aplicadas na indústria de bebidas e alimentícia, essencialmente na extração e clarificação de sumos, na melhora de propriedades organolépticas do vinho, no aumento da eficiência de extração de óleos vegetais, na aceleração da fermentação do café e chá, como aditivos alimentares de aves domésticas e ruminantes, e na sacarificação de resíduos agrícolas ricos em pectina, o que pode ser aproveitado para a geração de etanol (BIZ et al., 2014). Existem poucos trabalhos na literatura sobre actinobactérias produtoras de pectinases. Na maior parte dos relatos existentes, as enzimas pectinolíticas desses procariotos são pectato liases, com a maior fração das cepas investigadas pertencendo ao gênero Streptomyces. JACOB et al., 2008 isolaram actinobactérias geradoras dessas enzimas, e uma das amostras, identificada como Streptomyces lydicus, foi eficaz no tratamento de fibras leves de banana.

A produção de enzimas hidrolíticas é um dos mecanismos pelos quais as bactérias endofíticas entram na planta, ganhando acesso principalmente pelas raízes. Exoenzimas que degradam polissacarídeos de origem vegetal exercem funções importantes em uma série de interações planta-micro-organismo e na colonização intracelular dos micro-organismos nas raízes. Contudo, já foi observado que a atividade dessas enzimas é maior no estágio de entrada dessas bactérias no interior da epiderme radicular e nunca depois das mesmas se estabelecerem nos espaços intracelulares do córtex das raízes. Além disso, a ideia de que essas bactérias entram na planta primariamente por excreção ativa enzimática é controversa, já que bactérias residentes de solo possuem uma maior frequência de enzimas hidrolíticas do que as que habitam o xilema. Isso levanta a hipótese de que a liberação dessas enzimas por esses organismos somente se faz necessária na fase inicial de invasão na planta e não depois de já estarem vivendo no tecido vegetal (HALLMANN et al., 1997; AMARESAN et al., 2014).

Esse pressuposto poderia explicar a baixa frequência de atividade pectinolítica e a ausência da detecção de atividade celulolítica entre os microorganismos endofíticos isolados no presente trabalho. Ainda não se entende completamente como funciona esse mecanismo de regulação da geração dessas exoenzimas. Todavia, acredita-se fortemente que uma forma de sinalização, como o quorum sensing, estaria envolvida no controle de qual fase de vida dessas bactérias que a expressão dos genes codificantes dessas proteínas catalíticas seria ativada. Curiosamente, as plantas perceberiam e podem coordenar essas respostas de sinalização dos endofíticos, participando ativamente no processo de origem da simbiose (EL-DEEB et al., 2012).

Pesquisas com o objetivo de isolar, caracterizar e determinar potencialidades biotecnológicas de micro-organismos de plantas nativas do Cerrado 
brasileiro são raras (MAITAN, 1998) e praticamente nulas aquelas pesquisas realizadas com plantas medicinais. A exemplo do presente estudo, CARRIM et al., (2006), em um trabalho conduzido pelo presente grupo de pesquisa, realizou o isolamento e triagem da produção de amilases, lipases, esterases e proteases de endofíticos de Jacaranda decurrens Cham. ("carobinha-do-campo"). Após a identificação, os 18 isolados foram agrupados em 10 espécies, com predomínio de bactérias dos gêneros Bacillus, Pseudomonas, Corynebacterium, Actinomyces e Staphylococcus, respectivamente. Quase todos os isolados exibiram pelo menos uma das atividades enzimáticas. Esse foi o primeiro trabalho de varredura da geração de exoenzimas em meio sólido por endofíticos de uma planta nativa do Cerrado brasileiro utilizada em fitoterapia, servindo como base para outros estudos na área de bioprospecção de micro-organismos endofíticos.

JALGAONWALA \& MAHAJAN (2011) efetuaram o isolamento e avaliação da atividade de várias enzimas extracelulares de endofíticos das plantas medicinais Aloe vera (L.) Burn. F, Curcuma longa L., Eucalyptus globules Dehnh, Musa paradiasa L., Pongamia glabra Vent., Vinca rosea (L.) G. Don e Withania somnifera (L.) Dunal. Foi recuperado um total de 14 isolados bacterianos e 23 fúngicos. As amostras de bactérias endofíticas demonstraram uma maior atividade enzimática quando comparado com os fungos selecionados. Foi verificada também uma certa gradação da atividade enzimática, com a maior parte dos isolados exibindo a capacidade de geração de proteases e amilases, sendo que na presente pesquisa a maioria das amostras exibiram atividade para proteases e esterases. É importante salientar que os autores em questão aplicaram a mesma metodologia para triar a produção dessas enzimas, ou seja, o método de difusão radial em meio sólido com determinação do IE.

\section{Atividade antibacteriana dos micro-organismos endofíticos isolados}

Dos 39 micro-organismos isolados da planta, observa-se que 15 (38,5\%) inibiram o crescimento de um ou mais dos micro-organismos indicadores avaliados (Tabelas 3 e 4). Os isolados Pseudomonas aeruginosa MC 7B e Pseudomonas fluorescens MC 15 apresentaram atividade antibacteriana contra a maioria das cepas indicadoras testadas, $15(93,8 \%)$ e 9 (56,2\%), respectivamente. Quatro isolados de Streptomyces isolados exibiram atividade antibacteriana frente a diferentes micro-organismos indicadores. O isolado Streptomyces sp. MC 30 destacou-se entre os demais do mesmo gênero, principalmente pelo alto grau de inibição contra algumas das cepas testadas, refletido pelo diâmetro da zona superior a $20 \mathrm{~mm}$ (dados não mostrados).

É concebível que as plantas, essencialmente as consideradas medicinais, alberguem micro-organismos que mimetizam a química dos compostos bioativos geradas pelo vegetal, o que pode levar a produtos naturais com um nível de atividade biológica maior que o original do vegetal (STROBEL, 2003). Sabe-se que várias moléculas bioativas que se pensavam ser originais do vegetal são, na verdade, produtos metabólicos exclusivos dos micro-organismos endofíticos. BRADER et al., (2014) comentam que esses organismos ainda podem exercer influência direta sobre a geração desses metabólitos secundários dos vegetais por meio de intervenção no crescimento e tolerância ao estresse nas plantas, além da produção compartilhada dessas substâncias entre o vegetal e o micro-organismo. 
TABELA 3 Atividade antibacteriana dos isolados endofíticos de Hyptis suaveolens (L.) Poit frente aos micro-organismos indicadores gram-positivos.

\section{Bactérias indicadoras}

Micro-organismos isolados

\begin{tabular}{|c|c|c|c|c|c|c|}
\hline 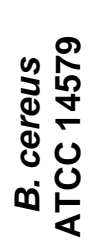 & 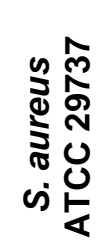 & 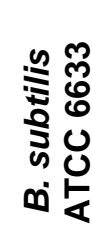 & 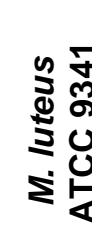 & 政 & & \\
\hline
\end{tabular}

\begin{tabular}{lllllllll}
\hline Pseudomonas fluorescens MC 2A & + & + & + & - & + & - & - \\
Pseudomonas fluorescens MC 15 & & + & + & + & + & + & - & + \\
Pseudomonas fluorescens MC 5A & + & + & + & + & + & - & - \\
Pseudomonas aeruginosa MC 7B & + & - & + & + & + & + & + \\
Pseudomonas stutzeri MC 2B & + & + & - & - & + & - & - \\
Pseudomonas sp. MC 33 & - & - & - & - & - & - & + \\
Comamonas acidovirans MC 5B & & + & + & - & - & + & + & + \\
Bacillus sp. MC 1A & - & - & - & - & - & - & - \\
Bacillus sp. MC 1B & - & - & - & + & - & - & - \\
Bacillus sp. MC 3 & - & - & - & + & - & - & - \\
Bacillus sp. MC 32 & - & - & - & - & - & - & - \\
Streptomyces sp. MC 30 & + & - & + & - & - & - & - \\
Streptomyces sp. MC 18 & - & - & + & - & - & - & - \\
Streptomyces sp. MC 43 & + & - & + & - & - & - & - \\
Streptomyces sp. MC 44 & - & - & + & - & - & - & - \\
\hline
\end{tabular}

+ = atividade antibacteriana; - = ausência de atividade antibacteriana.

TABELA 4 Atividade antibacteriana dos isolados endofíticos de Hyptis suaveolens (L.) Poit frente aos micro-organismos indicadores gram-negativos.

\section{Bactérias indicadoras}

Micro-organismos isolados

Pseudomonas fluorescens MC 2A

Pseudomonas fluorescens MC 15

Pseudomonas fluorescens MC 5A

Pseudomonas aeruginosa MC 7B

Pseudomonas stutzeri MC 2B

Pseudomonas sp. MC 33

Comamonas acidovirans MC 5B

Bacillus sp. MC 1A

Bacillus sp. MC 1B

Bacillus sp. MC 3

Bacillus sp. MC 32

Streptomyces sp. MC 30

Streptomyces sp. MC 38

Streptomyces sp. MC 43

Streptomyces sp. MC 44

\section{Bacterias indicadoras}

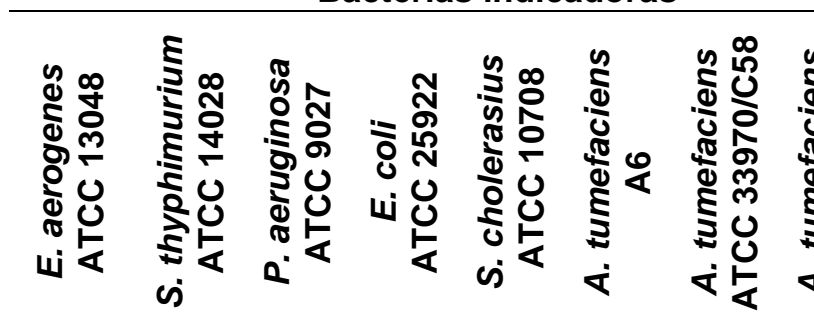

$\sum_{\substack{0 \\ 0}}^{0} \frac{1}{0}$

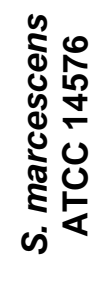

$+=$ atividade antibacteriana; - = ausência de atividade antibacteriana

Com exceção às actinobactérias, a avaliação da atividade antibacteriana das demais bactérias isoladas testadas foi realizada conforme a metodologia de ROMEIRO (1989), ou seja, analisou-se a capacidade de geração de bacteriocinas ENCICLOPÉDIA BIOSFERA, Centro Científico Conhecer - Goiânia, v.11 n.22; p.3048 
por esses endofíticos. Bacteriocinas são peptídeos gerados por bactérias que inibem ou matam outros organismos. A atividade in vitro dessas biomoléculas é predominante frente a micro-organismos gram-positivos. A ação contra bactérias gram-negativas ocorre em menor extensão e é mais comumente encontrada quando o organismo produtor da bacteriocina é gram-negativo (BALCIUNAS et al., 2013; COTTER et al., 2013). É preciso um aprofundamento do estudo para confirmação da natureza bacteriocinogênica dos compostos com atividade antibacteriana gerados pelos endofíticos isolados no presente estudo. Analisando-se os resultados obtidos nessa triagem, observa-se que os isolados do gênero Pseudomonas se sobressaíram frente as demais quanto a bioatividade. Bacteriocinas de endofíticos desse gênero são amplamente exploradas para o biocontrole de fitopatógenos (RAMESH et al., 2009; DONG et al., 2010).

MCCAUGHEY et al., (2014) recentemente comprovaram que os receptores-

alvo dessas substâncias de natureza peptídica de Pseudomonas são lipopolissacarídeos geralmente contendo D-ramnose, especificidade que possibilitam que essas proteínas antibióticas tenham uma toxicidade seletiva de interessante aplicação não somente para o controle biológico de pragas microbianas como também no tratamento de infecções por cepas multirresistentes de $P$. aeruginosa, com um mínimo impacto ambiental.

A biossíntese de substâncias semelhantes a bacteriocinas por diferentes micro-organismos pode ser, em alguns casos, induzida pelo tratamento das cepas estudadas por mitomicina $\mathrm{C}$ ou a luz ultravioleta. Nas bactérias endofíticas estudadas, excetuando-se Streptomyces, esse processo ocorreu espontaneamente, sem a necessidade de adição desses agentes indutores (IACOBELLIS et al., 1995).

A pesquisa por actinobactérias endofíticas de plantas medicinais começou a se desenvolver nos últimos anos. QIN et al., (2011) argumentam que os procariotos desse filo isolados de vegetais de uso popular na medicina tradicional exibem a capacidade de produzir metabólitos de natureza química inédita e com múltiplas ações que se estendem desde a antimicrobiana a imunossupressora. A maior parte dos isolados endofíticos de actinobactérias de ervas medicinais são estreptomicetos, a distribuição similar encontrada para actinobactérias habitantes de solos e demais ambientes terrestres.

No atual trabalho, foram isolados actinobactérias somente do gênero Streptomyces. MINI (2012) efetuou o isolamento de 47 actinobactérias endofíticas de quatro plantas medicinais indianas e avaliou a atividade biocida frente a diferentes isolados de fungos fitopatogênicos, com dois isolados de Streptomyces se destacando quanto a ação antifúngica. PASSARI et al., (2015) recuperaram 49 isolados de actinobactérias a partir de sete plantas de emprego comum na medicina popular indiana, com $66,6 \%$ dos isolados identificados como Streptomyces e pelo menos $22,2 \%$ apresentando atividade antagonista frente a, pelo menos, dois dos quatro patógenos testados e todos esses positivos para $S$. aureus e E. coli. Com base nos resultados adquiridos na varredura da ação antagonista dessas cepas, almeja-se futuramente realizar a produção em maior escala, avaliação da atividade antimicrobiana contra patógenos gram-positivos multirresistentes e purificação dos metabólitos antibióticos do isolado Streptomyces sp. MC 30.

\section{CONCLUSÕES}

Um total de 39 micro-organismos endofíticos foram isolados de todas as partes da planta medicinal Hyptis suaveolens (L.) Poit., com uma ampla diversidade cultivável, envolvendo bactérias gram-positivas, gram-negativas e uma levedura. Os 
isolados microbianos endofíticos de Hyptis suaveolens (L.) Poit. exibem potencial como produtores de exoenzimas de interesse biotecnológico, com predomínio da produção de proteases e esterases, além de metabólitos secundários e compostos de natureza bacteriocinogência frente a vários micro-organismos indicadores. $O$ presente trabalho consiste no segundo na área de bioprospecção de endofíticos de plantas nativas do Cerrado brasileiro utilizadas em fitoterapia, e evidencia a necessidade de uma pesquisa mais ativa na área da exploração do potencial biotecnológico do microbioma natural desse bioma.

\section{REFERÊNCIAS}

ABAGLI, A. Z.; ALAVO, T. B. C.; AVLESSI, F.; MOUDACHIROU, M. Potential of the bush mint, Hyptis suaveolens essential oil for personal protection against mosquito biting. Journal of the American Mosquito Control Association, v. 28, n. 1, p. 1519, 2012.

ADRIO, J. L.; DEMAIN, A. L. Microbial enzymes: tools for biotechnological processes. Biomolecules, v. 4, p. 117-139, 2014.

AMARESAN, N.; JAYAKUMAR, V.; THAJUDDIN, N. Isolation and characterization of endophytic bacteria associated with chilli (Capsicum annuum) grown in coastal agricultural ecosystem. Indian Journal of Biotechnology, v. 13, n. 2, p. 247-255, 2014.

ANBU, P.; GOPINATH, S. C. B.; CIHAN, A. C.; CHAULAGAIN, B. P. Microbial enzymes and their application in industries and medicine. BioMed Research International, v. 2013, p. 1-2, 2013.

ARAÚJO, L. W.; LIMA, A. O. S.; AZEVEDO, J. L.; MARCON, J.; SOBRAL, J. K.; LACAVA, P. T. Manual: isolamento de microrganismos endofíticos. 1 ed. Piracicaba: CALQ, 2002. 86 p.

BALCIUNAS, E. M.; MARTINEZ, F. A. C.; TODOROV, S. D.; FRANCO, B. D. G. M.; CONVERTI, A.; OLIVEIRA, R. P. S. Novel biotechnological applications of bacteriocins: a review. Food Control, v. 32, n. 1, p.134-142, 2013.

BAUER, A. W.; KIRBY, W. M.; SHERRIS, J. C.; TURCK, M. Antibiotic susceptibility testing by a standardized single disk method. American Journal of Clinical Pathology, v. 45, n. 4, p. 493-496, 1966.

BECKER, B.; LECHEVALIER, M. P.; GORDON, R. E.; LECHEVALIER, H. A. Rapid differentiation between Nocardia and Streptomyces by paper chromatography of whole-cell hydrolysates. Applied Microbiology, v. 12, n. 5, p. 421-423, 1964.

BIZ, A.; FARIAS, F. C.; MOTTER, F. A.; PAULA, D. H.; RICHARD, P.; KRIEGER, N.; MITCHELL, D. A. Pectinase activity determination: an early deceleration in the release of reducing sugars throws a spanner in the works. PLoS ONE, v. 9, n. 10, 2014.

BORNSCHEUER, U. T. Microbial carboxyl esterases: classification, properties and application in biocatalysis. FEMS Microbiology Reviews, v. 26, n. 1, p. 73-81, 2002. 
BRADER, G.; COMPANT, S.; MITTER, B.; TROGNITZ, F.; SESSITSCH, A. Metabolic potential of endophytic bacteria. Current Opinion in Biotechnology, v. 27, p. 30-37, 2014.

CARRIM, A. J. I.; BARBOSA, E. C.; VIEIRA, J. D. G. Enzymatic activity of endophytic bacterial isolates of Jacaranda decurrens Cham. (Carobinha-do-campo). Brazilian Archives of Biology and Technology, v. 49, n. 3, p. 353-359, 2006.

CORRÊA, R. C. G.; RHODEN, S. A.; MOTA, T. R.; AZEVEDO, J. L.; PAMPHILE, J. A.; SOUZA, C. G. M.; POLIZELI, M. L. T. M.; BRACHT, A.; PERALTA, R. M. Endophytic fungi: expanding the arsenal of industrial enzyme producers. Journal of Industrial Microbiology and Biotechnology, v. 41, n. 10, p. 1467-1478, 2014.

COTTER, P. D.; ROSS, R. P.; HILL, C. Bacteriocins - a viable alternative to antibiotics. Nature Reviews Microbiology, v. 11, n. 2, p. 95-105, 2013.

DONG, F.; ZHANG, X. H.; LI, Y. H.; WANG, J. F.; ZHANG, S. S.; HU, X. F.; CHEN, J. S. Characterization of the endophytic antagonist pY11T-3-1 against bacterial soft rot of Pinellia ternata. Letters in Applied Microbiology, v. 50, n. 6, p. 611-617, 2010.

DUDEJA, S. S.; SUNEJA, P.; SAINI, R. Interaction of endophytic microbes with legumes. Journal of Basic Microbiology, v. 52, n. 2, p. 248-260, 2012.

EL-DEEB, B.; BAZAID, S.; GHERBAWY, Y.; ELHARIRY, H. Characterization of endophytic bacteria associated with rose plant (Rosa damascena trigintipeta) during flowering stage and their plant growth promoting traits. Journal of Plant Interactions, v. 7, n. 3, p. 248-253, 2012.

FUNGARO, M. H. P.; MARCCHERONI, J. W. Melhoramento genético para produção de enzimas aplicadas à Indústria de Alimentos. In: __. MELO, I. S.; VALADARES-INGLIS, M. C.; NASS, L. L.; VALOIS, A. C. C. (ed.). Recursos genéticos e melhoramento - microrganismos. Jaguariúna: Embrapa Meio Ambiente, 2002. p. 426-453.

GHORBEL, S.; KAMMOUN, M.; SOLTANA, H.; NASRI, M.; HMIDET, N. Streptomyces flavogriseus HS1: Isolation and Characterization of Extracellular Proteases and their compatibility with laundry detergents. BioMed Research International, v. 2014, p. 1-8, 2014.

GUPTA, R.; BEG, Q. K.; LORENZ, P. Bacterial alkaline proteases: molecular approaches and industrial applications. Applied Microbiology and Biotechnology, v. 59, n. 1, p. 15-32, 2002.

GUTIERREZ, R. M. P.; GONZALEZ, A. M. N.; RAMIREZ, A. M. Compounds derived from endophytes: a review of Phytochemistry and Pharmacology. Current Medicinal Chemistry, v. 19, n. 18, p. 2992-3030, 2012. 
HALLMANN, J.; QUADT-HALLMANN, A.; MAHAFFEE, W. F.; KLOEPPER, J. W. Bacterial endophytes in agricultural crops. Canadian Journal of Microbiology, v. 43, n.10, p. 895-914, 1997.

HANKIN, L.; ANAGNOSTAKIS, S. L. The use of solid media for detection of enzyme production by fungi. Mycologia, v. 67, n. 3, p. 597-607, 1975.

HANKIN, L.; ZUCKER, M.; SANDS, D. C. Improved solid medium for the detection and enumeration of pectolytic bacteria. Applied Microbiology, v. 22, n. 2, p. 205209, 1971.

HARDOIM, P. R.; VAN OVERBEEK, L. S.; PIRTTILA, A. M.; COMPANT, S.; CAMPISANO, A.; DORING, M.; SESSITSCH, A. The hidden world within plants: ecological and evolutionary considerations for defining functioning of microbial endophytes. Microbiology and Molecular Biology Reviews, v. 79, n. 3, p. 293-320, 2015.

IACOBELLIS, N. S.; CONSTESINI, A. M.; SUCRICO, G. Bacteriocin production by Pseudomonas syringae subsp. Savastanoi. Phytopathologia Mediterranea, v. 34, n. 1, p. 15-22, 1995.

ISLAM, A. K. M. M.; OHNO, O.; SUENAGA, K.; KATO-NOGUCHI, H. Suaveolic acid: a potent phytotoxic substance of Hyptis suaveolens. The Scientific World Journal, v. 2014, p. 1-6, 2014.

JACOB, N.; NILADEVI, K. N.; ANISHA. G. S.; PREMA, P. Hydrolysis of pectin: An enzymatic approach and its application in banana fiber processing. Microbiological Research, v. 163, n. 5, p. 538-544, 2008.

JALGAONWALA, R.E.; MAHAJAN, R.T. Evaluation of hydrolytic enzyme activities of endophytes from some indigenous medicinal plants. Journal of Agricultural Technology, v. 7, n. 6, p.1733-1741, 2011.

JESUS, N. Z. T.; FALCÃO, H. S.; LIMA, G. R. M.; CALDAS-FILHO, M. R. D.; SALES, I. R. P.; GOMES, I. F.; SANTOS, S. G.; TAVARES, J. F.; BARBOSA-FILHO, J. M.; BATISTA, L. M. Hyptis suaveolens (L.) Poit (Lamiaceae), a medicinal plant protects the stomach against several gastric ulcer models . Journal of Ethnopharmacology, v. 150, n. 3, p. 982-988, 2013.

KADO, C. I.; HESKETT, M. G. Selective media for isolation of Agrobacterium, Corynebacterium, Erwinia, Pseudomonas and Xanthomonas. Phytopathology, v. 60, n. 6, p. 969-976, 1970.

KASHIWAGI, N.; MIYAKE, M.; HIROSE, S.; SOTA, M.; OGINO, C.; KONDO, A. Cloning and starch degradation profile of maltotriose-producing amylases from Streptomyces species. Biotechnology Letters, v. 36, n. 11, p. 2311-2317, 2014.

LIN, J. E.; CHANG, D. C. N.; SHEN, G. J.; WANG, H.Y. Correlations among several screening methods used for identificatifying wood-decay fungi that can degrade toxic chemicals. Biotechnology Techniques, v. 5, n. 4, p. 275-280, 1991. 
MAITAN, V. R. Isolamento e caracterização de actinomicetos endofíticos isolados de Solanum lycocarpum (lobeira). 1998. 122 p. Dissertação (Mestrado em Ciências Biológicas) - Universidade Federal de Goiás, Goiânia, Brasil, 1998.

MARTINS, F. T.; POLO, M. Desenvolvimento reprodutivo de Hyptis suaveolens (L.) Poit.: relação entre fotoperíodo, densidade celular meristemática e padrão de expressão de um ortólogo putativo do gene LEAFY de arabidopsis. Revista Brasileira de Botânica, v.32, n.1, p.131-142, 2009.

MCCAUGHEY, L. C.; GRINTER, R.; JOSTS, I.; ROSZAK, A. W.; WALOEN, K. I.; COGDELL, R. J.; MILNER, J.; EVANS, T.; KELLY, S.; TUCKER, N. P.; BYRON, O.; SMITH, B.; WALKER, D. Lectin-like bacteriocins from Pseudomonas spp. utilise Drhamnose containing lipopolysaccharide as a cellular receptor. PLOS Pathogens, v. 10, n. 2, 2014.

MINI, P. R. Endophytic actinomycetes from Indian medicinal plants as antagonists to some phytopathogenic fungi. Open Access Scientific Reports, v. 1, n.4, 2012.

MITSUKURA, K.; SHIMIZU, M.; MATSUSHITA, K.; YOSHIDA, T.; NAGASAWA, T. Characteristics and function of Alcaligenes sp. NBRC 14130 esterase catalysing the stereo-selective hydrolysis of ethyl Chrysanthemate. Journal of Applied Microbiology, v. 108, n. 4, p. 1263-1270, 2010.

NAIR, D. N.; PADMAVATHY, S. Impact of endophytic microorganisms on plants, environment and humans. The Scientific World Journal, v. 2014, p. 1-11, 2014.

NGOZI, L. U.; UGOCHUKWU, N.; IFEOMA, P. U.; CHARITY, E. A.; CHINYELU, E. The efficacy of Hyptis Suaveolens: a review of its nutritional and medicinal applications. European Journal of Medicinal Plants, v. 4, n. 6, p. 661-674, 2014.

OWEN, N. L.; HUNDLEY, N. Endophytes - the chemical synthesizers inside plants. Science Progress, v. 87, n. 2, p. 79-99, 2004.

PADALIA, H.; SRIVASTAVA, V.; KUSHWAHA, S. P. S. How climate change might influence the potential distribution of weed, bushmint (Hyptis suaveolens)?. Environmental Monitoring and Assessment. v. 187, n. 210, p. 1-14, 2015.

PANT, G.; PRAKASH, A.; PAVANI, J. V. P.; BERA, S.; DEVIRAM, G. V. N. S.; KUMAR, A.; PANCHPURI, M.; PRASUNA, R. G. Production, optimization and partial purification of protease from Bacillus subtilis, Journal of Taibah University for Science, v. 9, n. 1, p. 50-55, 2015.

PASSARI, A. K.; MISHRA, V. K.; SAIKIA, R.; GUPTA, V. K.; SINGH, B. P. Isolation, abundance and phylogenetic affiliation of endophytic actinomycetes associated with medicinal plants and screening for their in vitro antimicrobial biosynthetic potential. Frontiers in Microbiology, v. 6, n. 273, 2015.

QIN, S.; XING, K.; JIANG, J. H.; XU, L. H.; LI, W. J. Biodiversity, bioactive natural products and biotechnological potential of plant-associated endophytic 
actinobacteria. Applied Microbiology and Biotechnology, v. 89, n. 3, p. 457-473, 2011.

RAMESH, R.; JOSHI, A. A.; GHANEKAR, M. P. Pseudomonads: major antagonistic endophytic bacteria to suppress bacterial wilt pathogen, Ralstonia solanacearum in the eggplant (Solanum melongena L.). World Journal of Microbiology and Biotechnology, v. 25, n. 1, p. 47-55, 2009.

RANA, N.; WALIA, A.; GAUR, A. $\alpha$-amylases from microbial sources and its potential applications in various industries. National Academy Science Letters, v. 36, n. 1, p. 9-17, 2013.

ROMEIRO, R. S. Constatação da produção de bacteriocinas por isolamentos de bactérias fitopatogênicas. In: __ ROMEIRO, R. S. (ed.). Métodos em bacteriologia de plantas. Viçosa: Editora UFV, 1989. p. 163-172.

RUSENDI, D.; SHEPPARD, J. D. Hydrolysis of potato processing waste for the production of polyhydroxybutyrate. Bioresource Technology, v. 54, n. 2, p. 191196, 1995.

SCHULZ; B.; BOYLE, C. The endophytic continuum. Mycological Research, v. 109, n. 6, p. 661-686, 2005.

SHIRLING, E. B.; GOTTLIEB, D. Methods for characterization of Streptomyces species. International Journal of Systematic Bacteriology, v. 16, p. 313-340, 1966.

SIERRA, G. A. A simple method for the detection of lipolytic activity of microorganisms and some observations on the influence of the contact between cells and fatty substrates. Antonie van Leeuwenhoek, v. 23, n. 1, p. 15-22, 1957.

SMIBERT, R. M.; KRIEG, N. R. Phenotypic characterization. in methods for general and molecular bacteriology. In: GERHARDT, P.; MURRAY, R. G. E.; WOOD, W. A.; KRIEG, N. R. (eds.). Methods for general and molecular bacteriology. Washington D. C.: American Society for Microbiology, 1994. p. 607-654.

STAMFORD, T. L. M.; ARAÚJO, J. M.; STAMFORD, N. P. Atividade enzimática de microorganismos isolados de jacatupé (Pachyrhizus erosus L. Urban). Ciência e Tecnologia de Alimentos, v. 18, n. 4, p. 382-385, 1998.

STEPNIEWSKA, Z.; KUZNIAR, A. Endophytic microorganisms-promising applications in bioremediation of greenhouses gases. Applied Microbiology and Biotechnology, v 97, n. 22, p. 9589-9596, 2013.

STROBEL, G. Harnessing endophytes for industrial microbiology. Current Opinion in Microbiology, v. 9, n. 3, p. 240-244, 2006.

STROBEL, G.; DAISY, B. Bioprospecting for microbial endophytes and their natural products. Microbiology and Molecular Biology Reviews, v. 67, n. 4, p. 491-502, 2003. 
STROBEL, G.A. Endophytes as sources of bioactive products. Microbes and Infection, v. 5, n. 6, p. 535-544, 2003.

SURYANARAYANAN, T. S.; THIRUNAVUKKARASU, N.; GOVINDARAJULU, M. B.; GOPALAN, V. Fungal endophytes: an untapped source of biocatalysts. Fungal Diversity, v. 54, n. 1, p. 19-30, 2012.

THANGAM, E. B.; RAJKUMAR, G. S. Studies on the production of extracellular protease by Alcaligenes fecalis. World Journal of Microbiology and Biotechnology, v.16, n. 7, p. 663-666, 2000.

VERA-ARZAVE, C.; ANTONIO, L. C.; ARRIETA, J.; CRUZ-HERNÁNDEZ, G.; VELÁZQUEZ-MÉNDEZ, A. M.; REYES-RAMÍREZ, A.; SÁNCHEZ-MENDOZA, M. E. Gastroprotection of suaveolol, isolated from Hyptis suaveolens, against ethanolinduced gastric lesions in Wistar rats: role of prostaglandins, nitric oxide and sulfhydryls. Molecules, v. 17, n. 8, p.8917-8927, 2012.

VERMA, N.; THAKUR, S.; BHATT, A. K. Microbial lipases: industrial applications and properties: a review. International Research Journal of Biological Sciences, v. 1, n. 8, p. 88-92, 2012.

VIEIRA, J. D. G. Purificação e caracterização de uma alfa-amilase de Streptomyces sp. 1999. 96 f. Tese (Doutorado em Ciências Biológicas) - Instituto de Ciências Biomédicas, Universidade de São Paulo, São Paulo. 1999.

VITORINO, L. C.; SILVA, F. G.; LIMA, W. C.; SOARES, M. A.; PEDROSO, R. C. N.; SILVA, M. R.; DIAS, H. J.; CROTTI, A. E. M.; SILVA, M. L. A.; CUNHA, W. R.; PAULETTI, P. M.; JANUÁRIO, A. H. Metabolic response induced by endophytic fungi and bacteria in Hyptis marrubioides Epling in vitro microplants. Química Nova, v. 36, n. 7, p. 1014-1020, 2013.

VITORINO, L. C.; SILVA, F. G.; SOARES, M. A.; SOUCHIE, E. L.; LIMA, W. C. The isolation and characterization of endophytic microorganisms from Hyptis marrubioides Epling roots. African Journal of Biotechnology, v. 11, n. 64, p. 12766-12772, 2012a.

VITORINO, L. C.; SILVA, F. G.; SOARES, M. A.; SOUCHIE, E. L.; COSTA, A. C.; LIMA, W. C. Solubilization of calcium and iron phosphate and in vitro production of Indoleacetic acid by endophytic isolates of Hyptis marrubioides Epling (Lamiaceae). International Research Journal of Biotechnology, v. 3, n. 4, p. 47-54, 2012b.

YU, H. S.; ZHANG, L.; LI, L.; ZHENG, C. J.; GUO, L.; LI, W.; PEIXIN, S.; QIN, L. Recent developments and future prospects of antimicrobial metabolites produced by endophytes. Microbiological Research, v. 165, n. 6, p. 437-449, 2010.

ZHOU, J. Y.; ZHAO, X. Y.; DAI, C. C. Antagonistic mechanisms of endophytic Pseudomonas fluorescens against Athelia rolfsii. Journal of Applied Microbiology, v. 117, n. 4, p. 1144-1158, 2014. 